This article has been accepted for publication by the the Journal of Arts Management, Law and Society. It can be cited as follows:

Benghozi P.-J., Salvador E., Simon J.-P. (2017), "The race for innovation in the media and content industries: Legacy players and newcomers. Lessons for policy makers from the video game and cinema industries", The Journal of Arts Management, Law and Society, Special Issue Digital Cultural Policies in Comparison, edited by Jonathan Roberge and Philippe Chantepie, vol. 47, n. 5, pp. 346-360.

\title{
The race for innovation in the media and content industries: Legacy players and newcomers. Lessons for policy makers from the video game and cinema industries
}

\author{
*Pierre-Jean Benghozi, **Elisa Salvador, *** Jean-Paul Simon
}

* Benghozi Pierre-Jean: Research Director CNRS and Professor at the Ecole Polytechnique, Paris, France, (I3-CRG, Ecole Polytechnique, CNRS, Université ParisSaclay);

** Salvador Elisa: ESSCA School of Management, Paris, France.
e-mail: Elisa.SALVADOR@ @ essca.fr, phone +33141862001 , corresponding author;

**** Simon Jean-Paul: JPS Public Policy Consulting, Seville, Spain.

\begin{abstract}
How do media industries innovate? And how can they compete with powerful new competitors from the information technology world? Innovation is usually linked with high-tech, and "creativity" is associated to media and content industries (MCIs), even if these industries rely on various technologies. The article focuses on the video game and cinema industries. It presents the contrasting specific forms of innovation from these two selected industries. Cultural public policies have always been designed mainly to support the production of creative content and generate social welfare instead of focusing on technological innovations. In the last decades, all these industries underwent significant transformations of their production processes, not to mention the transformation due to the introduction of computers within the firms. The findings raised by recent studies provide a fresh understanding of the nature of innovation, and its place in these industries that does not boil down to simply creating new content. Instead, economic dynamics have recently been opened in creative and cultural companies: a regular capacity for innovation is observable. The paper blends a general outlook that sets the scene of the transformations these industries have gone through with some selected case studies to highlight some innovative elements. The evolution of the development models and the changes brought by technology raise questions about how to (re)consider the role of public intervention in the cultural and creative industries (CCIs).
\end{abstract}

Keywords: creative industries; video game industry; cinema industry; intermediaries; R\&D and innovation.

Benghozi Pierre-Jean is Research Director at the National Centre for Scientific Research (CNRS) and professor at Ecole Polytechnique (Paris). He developed, since the early eighties, a pioneering research group on Information Technology, Telecommunications, Media and Culture. Co-Chairman of AIMAC, the largest international Conference for Art and Culture Management, he is also board member of scientific committees in the highest French institutions, international scientific conferences 
and academic journals. He was also appointed commissioner and member of the executive board of the French national regulatory authority for electronic communications (ARCEP).

Salvador Elisa holds an international $\mathrm{PhD}$ in Institutions, Economics \& Law from the University of Turin (Italy). She has worked for the Italian National Research Council (CNR) on several projects focused on innovation policies. She has collaborated with the Polytechnic of Turin and with the ESCPEurope Business School, has been researcher at Ecole Polytechnique, Paris (2012-2015), and she has been also adjunct Professor at Iéseg School of Management, Economics and International Business Economics tracks (2014-2016). She is currently Assistant Professor at ESSCA School of Management, Management and Corporate Environment Department, and associate researcher at Ecole Polytechnique, Management Research Center.

Simon Jean-Paul runs a consulting firm specializing in media/telecom law regulation and strategy. He has held various positions in the telecom industry, and worked as a senior scientist at the Institute for Prospective Technological Studies (IPTS), European Commission, Directorate-General JRC. He holds a PhD in Philosophy and is a graduate (MBA) from the Ecole des Hautes Etudes Commerciales. He has written several books and articles on communications and public policy. He is a frequent speaker on telecommunications and media in Asia, Europe and the USA.

A preliminary but significantly different version of this paper was presented at the $2^{\text {nd }}$ International Multidisciplinary Workshop on Cultural Industries and digital platforms, Labex ICCA, November 14 15, 2016, Paris, France. 


\section{Introduction}

How do media industries innovate? In addition, how can they compete with powerful new competitors from the information technology world? Innovation is a pivotal issue but difficult to address in media and content industries (MCIs). As highlighted by Miles and Green (2008: p. 3), "we do not understand well the process of innovation within the creative industries, nor how waves of innovation from elsewhere impact upon them". Innovation ${ }^{1}$ is usually linked with high-tech, and "creativity" is associated to MCIs, even if these industries rely on various technologies. ${ }^{2}$ This has consequences on the role and the formulation of appropriate public policies: policy makers dealing with cultural and creative industries (CCIs) face many new challenges, as the digital economy follows different objectives and modes of regulation, with sometimes-contradictory features. The question, then, is to what extent can the distribution of online content support an economic model that is efficient and sustainable enough to finance the technological innovations associated with digital developments (Lash, Urry, 1994). Cultural public policies have always been designed from a supply perspective, mainly to support the production of creative content and generate social welfare. Moreover, public intervention in CCIs is built upon the externalities experienced by society at large (Unesco, 2005).

In general, "over the years, the concept of innovation has profoundly changed in economics and strategic management" (Benghozi, Salvador, 2016: 3). Most CCIs consider innovation as a "normal" aspect of business operations and strategy (Potts, 2009) and they may have trouble separating investments in projects from investments in innovation technologies.

The digital age supports disruptive economic changes in the CCIs: it alters the traditional business model of these industries. Digitization lowers entry barriers to newcomers such as technological suppliers, and gives a key role to new distribution channels such as aggregation platforms (Gawer, 2014; Benghozi, Salvador, 2014; Benhamou, 2014). As a result, the usual categories (disruptive/incremental, product/service, technolgy/service...) used to deal with innovation are challenged. CCIs are highly illustrative of this phenomenon of reshuffling. This broad dimension of innovation is in line with recent trends identified in the music, cinema and video game industries.

According to Cooke and De Propris (2011: 366), recent studies have found CCIs to be "more innovative than other manufacturing and service sectors." Notwithstanding, these industries are "only tangentially mentioned in Europe 2020, in relation to the European Union's agenda to promote a smart, as well as sustainable and inclusive growth; where smart growth means 'developing an economy based on knowledge and innovation'." And Foord (2008: 111) has called for "a deeper understanding of the innovation and production linkages" between CCIs and the other sectors of the knowledge economy. The European Union policy agenda for "smart" economic growth should take into account the concrete potentialities of innovations generated by these industries (Cooke, De Propris, 2011: 369-370). Additionally, CCIs are associated with various forms of "hidden ${ }^{3}$ innovation" (Barge-Gil et al., 2011; Brandellero, Kloosterman, 2010; Green et al 2007) and perceived to offer a limitless supply of new ideas for potential innovations. The debate about the nature of innovation investments in

\footnotetext{
${ }^{1}$ A detailed review about the paradoxical findings that explain the particular state of the literature on innovation in CCIs is provided in Benghozi and Salvador (2016). Even the studies that aim at investigating the potential of R\&D to support the CCIs (e.g. Cunningham et al., 2004; Foundation for RST, 2003) do not provide any analysis of the processes and/or technologies adopted.

2 This article is based on Benghozi, Salvador, Simon (2015) report.

${ }^{3}$ As highlighted by Watson and Taylor (2014: 2431): "One crucial element of the complexity of production in the cultural and creative industries is the issue of "hiddeness", that is to say the invisibility to policy, or lack of acknowledgement in policy, of particular actors and particular local creative practices".
} 
the creative value chain thus calls for a reversal of perspective in order to find ways to finance the significant risks associated with technological breakthrough innovations.

Cultural policies on this point share common features in different countries and sectors (Jaw et al, 2012). Yet, the contrasting cases of MCI subsectors show that these industries are coping in different ways with technological waves. In the last decades, they have undergone significant transformations in their production processes (digital recording, computerized editing of films, desktop publishing), as well as transformations due to the introduction of computers within firms (business processes). The video game and the cinema industries illustrate two different configurations of this: a recent industry born at the heart of technology versus a sector where the place of technology had always been independent from production (Cunningham et al., 2004).

Despite these differences, digital movements in the CCIs share common features (Muller et al., 2009): high variability and scalability of business models, the emergence of new external actors driven by technology and new forms of technical intermediation, industrial partnerships, and a rebalancing and sharing of value and investments. The place and the very nature of innovation in these industries do not boil down to simply creating new content. Instead, economic dynamics have recently been opened in CCIs: a regular capacity for innovation - deployed in very different ways - is observable.

Building on a previous analysis of the evolutions of the cinema industry (Benghozi et al., 2015), taking into account the main outputs of this research, the paper attempts to assess how these transformations could impact public policies, and whether legacy policies need reconsideration to keep up with the changes. To introduce another perspective, we contrasted this analysis of the cinema industry with that of the videogame industry.

These evolutions question cultural policies initially designed to deal with traditional approaches of innovation, based on the decoupling of technology and creation, thereby making them ill-adjusted to the changes. The paper attempts understanding how these transformations should lead to revamping the way policymakers have been grappling with cultural industries. In other words, it aims at questioning the prerequisites of cultural policies rather than offering new forms of intervention.

Therefore, this article presents the contrasting specific forms of innovation from the two selected industries: video games and cinema (Section 1). Section 2 explores more specifically the role played by information technology players in CCIs, as they have developed their technical intermediation functions in a new digital-based ecosystem (Benghozi, Salvador, 2014; Corallo et al., 2007). Finally, the third section highlights the consequences of these findings for a possible reconfiguration of cultural policies to accompany these transformations.

\section{The various roles played by technology in CCIs \\ 1.1 Online information and communication technologies as an engine of change: the case of video games}

The video game industry was "born digital" from the start and technology has played a pivotal role in its development and growth since the beginning. This industry promotes the proliferation of various forms of monetization, and business models, with regular new entrants who bring disruptive perspectives and the links with digital technology industries (equipment, operating systems, and telecom operators) are strong. Throughout its evolution, this industry has faced structured time cycles marked by the succession of technical innovations, renewal of games and new forms of monetization. The result is unprecedented forms of articulation between different technologies ${ }^{4}$ and competition between oligopolistic

\footnotetext{
${ }^{4}$ The recent move of Nintendo (Mario Bros) towards mobile games is a main example, as well as the success of Pokemon Go.
} 
gaming companies (like Sony, Nintendo, and Microsoft) and new actors driven by the timely success of certain games.

For its first thirty years, the video game sector relied on game consoles. Despite its relatively short history, this industry, with 1.2 billion active gamers worldwide as of 2013, has become a huge economic force that is expected to reach a turnover of US $\$ 102.7$ billion worldwide in 2017 (Newzoo, 2015a), addressing every kind of channel: personal computers, tablet, television, on-line and mobile phone.

The birth of the video game industry was concomitant with the emergence of the public microcomputer. This physical console market is currently offset by the development of new channels, web games, cloud gaming, and gaming on mobile devices. The industry saw the emergence of third-party development companies between the late 1980s and the early 1990s, creating the first separated middleware modules to handle graphics in videogames: Crytek and Trinigy emerged as the most popular core game engines (De Prato et al, 2010: 77). An additional set of companies currently provides data analytics tracking on how consumers interact with the "freemium" model of games: this is the case for Swrve ${ }^{5}$ or Ninja Metrics. By the same token, new big data tools and the growth of the mobile Internet triggered the creation of companies, providing all kind of metrics, panels, and analytics solutions, like AppAnnie, Flurry, or Datasift.

Since 2004, the online and wireless market has grown with remarkable rapidity, driven by an increase in the number of broadband subscribers, innovation in available games, the transition to handheld devices, and the newest generation consoles. Online and wireless video games have become the largest product segment of the industry. Newzoo gives the following distribution of revenues per screen in 2016 for an estimated global turnover of $\$ 99.6$ billion (Figure 1). The mobile segment is expected to reach $\$ 45$ billion by 2018 , a $23 \%$ compound annual growth rate since 2014 (Newzoo, 2015b).

Figure 1: Revenues per screen

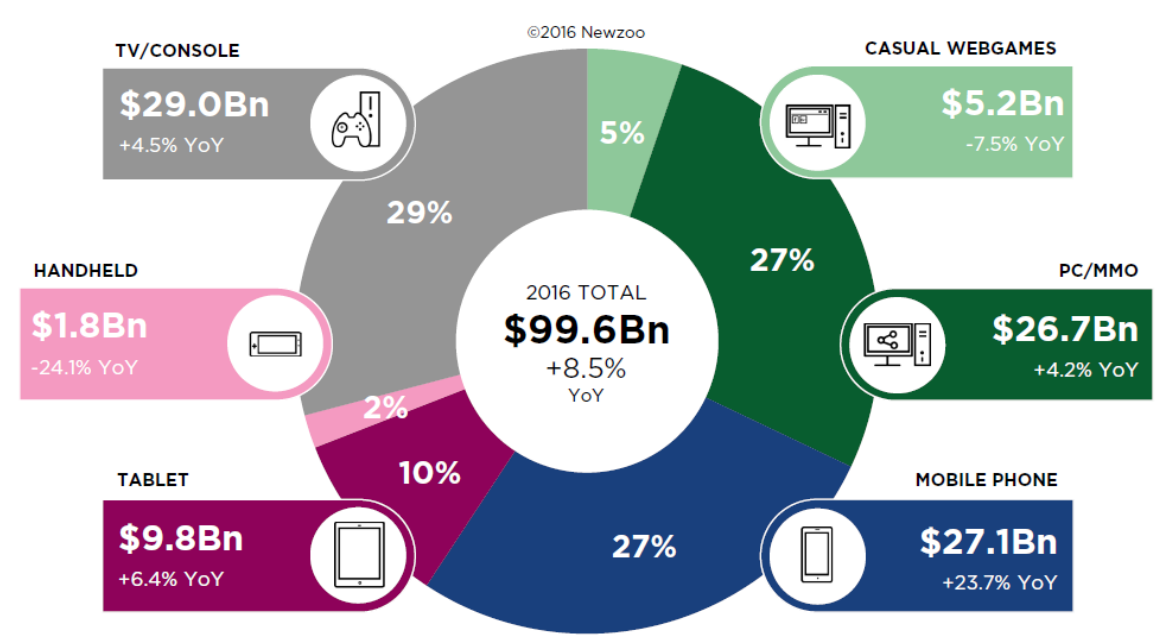

Source: Newzoo (2016), Global Games Marker Report Premium.

This diversification of delivery channels brought by mobile and online video games allowed for a shift from console games/packaged products and a handful of global publishers, to a self-publishing model (as illustrated with Rovio, the Finnish publisher of "Angry Birds"), which created opportunities for companies located in smaller markets to reach a global market. Social networks like Facebook also contributed to popularize games on these

\footnotetext{
${ }^{5}$ https://www.swrve.com/

$6 \underline{\mathrm{http}: / / \mathrm{www} \cdot \text { ninjametrics.com/about-ninja-metrics-and-the-founders }}$
} 
platforms (e.g. Zynga's "Farmville"), offering simple games based on servers allowing for the kind of interaction offered by massive multiplayer online games, and fuelling audience and revenue growth in the online games segment (De Prato, Simon, 2015). For example, Riot Games, a company founded in 2006, released its game "League of Legends" in 2009, which became the most played personal computer game ever, with over 67 million plays on average per month.

At the same time, the original business model of video games, inspired by publishers' boxed products (a game to install or use on a console) is outdated as business models become more diverse, now including pay-per-play, freemium, crowdfunding, bundling and subscriptionbased models. Indeed, free-to-play is now dominating the worldwide market for mobile games (Mobile Game Arch Roadmap, 2013). Furthermore, the advent of the Internet and mobile technology introduced highly disruptive business models, and newcomers and their innovative scenarios are re-shaping the global landscape of the traditional industry. The development of the mobile Internet supported the expansion of the video game sector, which currently represents now a significant share of sales on the Apple AppStore. As well, many Asian video-game giants were born online, like the now world Chinese leader Tencent.

Thus, online and mobile games acted as an engine of change within the video game industry. The alternative business models that users face when entering the world of online games are actually rather different from those they were used to (De Prato, 2014). Besides, as games are free (either partially or totally), this requires innovative ways to look for new revenue streams (virtual items, in-app purchases). Data analysis and mastering metrics have thus become pivotal for these new business models, which was not the case for boxed games, or even for online pay for games. These companies have thus become pioneers in the use of Big Data.

\subsection{Innovation in three main streams: The case of cinema}

Following the presentation of the video games industry, the case of cinema enables to pursue the discussion about the role of technology in CCIs and the subsequent role of public policies in these industries (Section 2 infra). To this aim, cinema industry was chosen mainly because of its paradigmatic value for public policy, as well as the contrast it offered to video games. If the video games industry was born "digital", among the historical CCIs, the cinema industry is the most technology-based. Its history has been shaped by technical innovations on a greater or lesser extent. The ubiquity of technology has helped to build a complex ecosystem that mixes various players in the technical, production and distribution sectors. Articulations between technical innovations and nature of content appeared in that case, therefore, particularly worth investigating.

From a strictly economic point of view, the cinema was arguably one of the first CCIs, and its seminal economic model was established at the beginning of the twentieth century. Cinema is organized as a service economy, on a rental basis, for the copies to be released in theatres and for viewers to pay for admission. Therefore, it historically structured itself around three different streams in terms of investment and business models: the structure of production (feature films), distribution (logistics for circulating copies and collecting revenues from ticket sales), and exhibition (network of the screens).

From a historical perspective, a number of prominent periods of technological change have affected the film sector more or less radically. Examples are provided by the introduction of sound film (1920s-1930s), color film (1930s-1960s), television screen (1950s-1960s), widescreen and 3D experiments (1950s), and home-video systems (1970s-1980s), (De Vinck, Lindmark, 2012: 20). During the past three decades, digital technologies have been introduced in the three main streams. Digital comes with cost-efficiencies, increased flexibility, and 
quality improvements in production. It also brings costs down for distribution, and for duplicating prints. $^{7}$

In particular, De Vinck and Lindmark (2012: 110) described how digitization has changed the theatrical exhibition landscape: digital cinema provides benefits in terms of consistent projection quality, programming flexibility (including alternative content) and cost savings associated with digital distribution. To illustrate this we can cite the case of UFO Moviez, a firm from Mumbai that claims to be the world's largest satellite-based digital cinema network. It has 4,000 digital screens across the globe delivering films directly to theatres, and ensuring "first day, first show" for film distributors and exhibitors across the country.

Disruptive technologies, like the spread of 3D, brought, therefore, market changes. In general, top-grossing films have a strong visual-effects component. Visual effects are presented as high-tech dream factories, helping filmmakers reduce the production costs of shooting outdoor scenes or recreating period settings. Nonetheless, the level of expertise necessary for high-quality visual effects is rare. The UK became a global center for visual effects work in commercials, and boasts some of the world's leading companies producing technology and tools for this industry (there are many specialist companies in Soho, London, that employ hundreds of animators, artists and programmers).

Otherwise, DreamWorks, a US animation film company, can be cited as an interesting example $^{8}$ of cooperation among firms with different technical resources, combining technology and the "artistic" dimension for the creation of full feature animation films. As CEO Katzenberg argues: "We have transformed over the years from hand-drawn animation to computer-generated films to being a leader in 3D entertainment. Our strategy has remained the same: to produce great stories that are creatively driven and technologically state-of-theart." 9

Looking at business model innovations, the virtual distribution exemplified by UFO Moviez opens a window of opportunity into the area of digital film distribution. A well-known example is provided by the French start-up Ymagis that developed a financial option (like a toll on the delivery of contents and a virtual print fee) to support the equipment of theatres for digital exhibition, thus blending financial and technical services. Ymagis assists cinema exhibitors tackle the digital revolution by providing financing to help them bear the costs of the transition from $35 \mathrm{~mm}$ to digital projection.

Online distribution is also something of a revolution in this area, progressing quickly with over 400 unique online services around the world. ${ }^{10}$ Additionally, the content community (cf. featuring companies such as Fox, Paramount, Sony, and Universal) has partnered with webbased companies like IBM and Microsoft, as well as manufacturers like Nokia, Sony, and Samsung), and digital rights management vendors in the digital entertainment content ecosystem to create "Ultraviolet". This is an interoperable platform for consumers to build, access, and share content libraries across devices and services - both within and outside the home. It remains to be seen whether this fast revolution will continue to progress at this rate.

\section{Information technology players surfing on innovations}

The digital revolution of MCIs is largely a revolution of intermediation in its various components. New players emerge and offer unprecedented solutions for aggregating and

\footnotetext{
${ }^{7}$ The theatrical 'digital print' is around ten times less expensive than a $35 \mathrm{~mm}$ film print (De Vinck, Lindmark, 2012).

${ }^{8}$ For further additional examples (like the American film company Zoetrope), cf. Benghozi et al. (2015).

${ }^{9}$ Company website, 2014, www.dreamworksanimation.com/media/insidedwa/ourculture/cat0/slide1.jpg

${ }^{10}$ Cf. www.mpaa.org/infographics-tell-the-story-behind-record-breaking-2013-at-the-box-office/\#.U4M8poW-
} $\underline{\mathrm{iUn}}$ 
distributing content, designing original terms of marketing and transaction adapted to this new framework (free subscriptions, micro-payments, virtual goods). "Intermediaries are organizations that emerge to perform such middleman services as brokering, facilitating, promoting and other value-adding activities between actors" (Laur et al., 2012: 1911). According to Benghozi and Paris (2014), intermediaries are "active third parties" operating alongside producers and consumers, in order to structure the offer of products or services.

This evolution towards new forms of intermediation is the main engine of the reorganization of cultural industries and technological infrastructure plays a key role in the success of these new cultural intermediaries (Benghozi, Salvador, 2015; Benghozi, Paris, 2014). Tran et al. (2011: 82) have argued "while the empirical literature offers substantial advance in understanding what innovation intermediaries do, there remains a lack of empirical insights on how they add value in particular sectors". An improvement is noticeable in recent years: for instance, the literature is focusing more and more on the role of intermediaries in CCIs ${ }^{11}$. The diffusion of the Internet has thus opened many reconfiguration possibilities encouraging experimentation of new forms of intermediation thank to online platforms and the dematerialization of reproduction.

While not new to the economy, the weight of platforms in the digital arena comes from the combination of several converging dimensions. They are organizing the supply and demand for content and services in two-sided markets ${ }^{12}$. Then, they provide a common base of technological development support for innovation, the basis on which different types of services or content can build on. Finally, these platforms are the backbone of a growing data economy, an integral part of the digital world.

\subsection{Powerful newcomers}

The weight of the technology is also the weight of intermediaries and economic actors supporting and supported by information and communication technologies (ICTs): Google, Amazon, Apple, and Internet Service Providers (ISPs). Their importance is incommensurately large compared with that of the cultural sector, which explains their ability to quickly build a place in the landscape of culture, using technological innovations to impose new economic models that have strongly disrupted the sectorial equilibria. Their characteristics can be quite different: large generalists (e.g. Google, Amazon) able to specify their offers by adapting them to specific market segments or types of products/services; new specialist players (e.g. Netflix) developing a particular product/service based on their expertise in the sector and the externalities of networks; and powerful new entrants thanks to the massive success of CCIs (e.g. Rovio, Dreamworks).

Public policies tend to address in different ways different categories of actors (legacy cultural players and newcomers of technology) irrespective of the fact that they all operate within the same extended digital ecosystem.

These various new players display specific value networks, including numerous technical intermediaries (Jakob, Van Heur, 2015) and "infomediaries" (Chantepie, Le Diberder, 2010), in contrast with past linear value chains. The output (books, CDs, films, videogames) is the result of new cooperation models between several actors (aggregators, distributors, technology providers) with different professional specializations. Such specific industrial

\footnotetext{
${ }^{11}$ Regional Studies has even recently dedicated a Special Issue to "Intermediaries and the Creative Economy" (2015).

12 A two-sided market combines three elements: 1 . The existence of two or more groups using the service, with different prices (asymmetric pricing). 2. The existence of crossed network externalities between these groups (a group being all the more attracted by the platform that the participation of the other group is important). 3 . The importance of the price-structure, i.e. not only the sum paid on the whole by the two groups but also the decomposition of this sum between the two groups. One side of the market becomes an input for the other side. See also Jitendra (2009).
} 
partnerships may not be conceived in the traditional sense, but rather as a set of industrial relations of "networked collaborators" within an ecosystem, or a combination of horizontal and vertical relationships throughout the layers of the ecosystem (Benghozi, Salvador, 2014). Technological strategic partnerships trigger the re-arrangement of the business ecosystem, and digitization unifies the entire value chain (from creation/production to consumption), which has been drastically altered and is becoming more complex.

Information technology players are bringing new kind of expertise but are keener to explore and establish new forms of interactions with their customers that legacy players were either reluctant or unable to develop due to lack of technical expertise. They also pioneer the use of data mining for compiling viewers' recommendations (Amazon, Netflix, Pandora, Spotify, and Zynga). Amazon is making the best out of the sophisticated ecosystem the company has built around its Kindle since 2007. The media giant from Seattle is now trying to duplicate its successful experience around a new ecosystem for audio-visual contents based on its new device Fire, launched in 2014, and the company has since created its own studios to invest in original content. It commissioned its own original content TV shows, releasing in 2013 the successful series “Alpha's House" (Simon, 2015). Google owns its own studios as well. YouTube started exploiting amateur video, a move that left initially legacy players skeptical, but not Google, who bought the company fast enough; only one year after the site was launched. The company anticipated new forms of demand, a new blend of supply and demand brought by user generated contents (Simon, 2016a).

Netflix provides an interesting case of a niche provider, morphing into a global digital company emerging from the very antiquated video home system renting model. The company was established in 1997 as an online solution to the problem of late fees when renting movies. The company interacts with various players within a complex network of commercial relationships and describes itself as "an ecosystem for Internet-connected devices" (Netflix, 2014: 1). Indeed, Netflix designed its strategy under three main assumptions: that Internet TV is replacing linear TV, that apps are replacing channels, and that screens are proliferating.

\subsection{Specialized technological suppliers as middlemen ${ }^{13}$}

Some other companies involved in the media and content value network usually attract less attention. This is the case of specialized technological suppliers that are building their positions using their technological expertise to serve the creative dimension of media production and cultural works. These specialists can either be insiders, as is the case in the cinema: actors emerge (at least currently) inside the sector. In other cases, they are outsiders, such as in video game companies. ${ }^{14}$

Digitization has thus opened up opportunities for an array of smaller or independent players, mostly software companies, to achieve more competitive positions in the value network. They grow through digitization and the deployment of the Internet. For instance, Akamai, founded in 1998 at MIT, use advanced computing techniques to deliver a streamlined web experience to end users. With over 170,000 servers in 92 countries over 1,200 networks, it is the leading provider of cloud services for delivering, optimizing and securing online content and business applications for large media companies, ranking ahead of AmazonCloudFront (Benghozi, Simon, 2016). These specialized new technology suppliers have mastered ICT skills overall, but are active and specialized in only a small number of technical areas. Their growth model places particular emphasis on specific operations - rather unusual in the media industry - such as the management of assets, patenting, and innovative technological spillovers. These companies are playing the role of the "new middlemen," liaising between the different layers of the ICT ecosystem.

\footnotetext{
${ }^{13}$ Cf. for details Simon et al. (2015)

${ }^{14}$ Or, historically, in the cinema in the past: cf. sound pictures or TV
} 
This somehow "golden age" of the CCIs is not without tensions between the diversification of channels, flows, terminals, and uses on the one hand, and the convergence of platforms and creation of an undifferentiated mass audience on the other. They are the result of the reorganization of the value chain, marked by the multiplication of business models, as well as an unprecedented competition between producers, broadcasters, ISPs, and OTTs. ${ }^{15}$ These tensions are sources of uncertainty for economic players and pose new challenges for the regulator. In audiovisual, for instance, new service providers from sectors with different technical and economic practices compete with traditional incumbents without the same regulatory or financial constraints (production obligations, quotas, diversity, youth protection, privacy).

\section{Looking back/looking forward: Policies for the digital age.}

Public policies for CCIs are facing several alternatives. A first perspective, which is rather dominant, consists of devising sector-specific policies in parallel, by importing cultural policies conceived historically, according to the type of content or art. A second approach focuses on public policies for actors rather than sectors: this is the case of measures in favor of creative clusters, distribution, and financing or support to new creative firms (Foord, 2008). A third perspective looks at orientating technological policies towards CCIs rather than at adapting cultural policies to the new environment: it is a matter of facilitating the access of CCIs to broader support programs. This has been the approach of the European Commission, for instance, so as to complement the Member states initiatives. Nonetheless, the implementation of these policies calls for an additional standpoint on concrete modalities of application for subsidy and financial support, sectorial regulation, redistribution of value by taxes, ecosystems, and business support.

\subsection{Policies for global competition: some reflections from the video games industry}

The video game industry received much attention from policy-makers in countries like Canada $^{16}$ and South Korea, which designed strong proactive sectorial policies over the last decade. In New Zealand, for example, "game production companies are not competing directly with other companies locally but with the rest of the world" (Ministry of Economic Development, 2012: 38). Quebec has claimed a 600\% growth in the games business since 2003 and shows an impressive track record: the creation of nearly 9,000 jobs, over 90 companies, many of which are international leaders (Noreau, 2013: 1). This output is the result of both federal and state government policies. These include not only tax breaks but also Canada's location, its education system focused on the industry's needs, the fact that it offers an attractive location for employees, has a highly creative workforce, is a cost effective location, and has among the lowest tax rates in North America.

In South Korea, government involvement took place as online gaming was being progressively recognized as a serious and growing industry. In 2000, the country launched a complex local cultural industrial program to promote the local cultural industry, and public support programs were set up to boost the development of local cultural industries (Choi, 2010). The South Korean government also set up development agencies through the Game Industry Promotion Act of 2006. Other accompanying measures were introduced: creation of a Game Rating Board, an official certification system (for game planners, computer graphic designers, and programmers), and an alternative to military service to provide skilled workers for key (eligible) industries (Wi, 2009). It is worth noting that these cases show long-term policies that are consistent with existing approaches by both governments. In the Canadian

\footnotetext{
15 Over The Top providers refer to companies offering services on top of a network.

${ }^{16}$ Cf. Hamac Conseils (2014), "étude comparative des crédits d'impôts en Europe et au Canada cinéma, audiovisuel, jeux vidéo”, Canada, pp. 53-81.
} 
case, government interventions since World War II have helped create the basis of a national cinema in animation and documentary. In South Korea, the emphasis on the ICT sector dates back to the recovery from the 1997 economic crisis.

Most European Union Member States have put in place tax credits for research (like tax deductions for R\&D). However, the picture is more contrasted, as only a few countries (France, the Nordic countries, and the UK to a much lesser extent) have been developing specific policies lately. Nordic countries are leaders in Europe for online and mobile games, and two countries in particular have developed specific policies for games: Iceland and Norway. Finland tried to mitigate the collapse of the Nokia model and came up with some policies to support a fast-growing industry, with global leaders like Rovio (publisher of Angry Birds) and Supercell (publisher of Clash of Clans). In France, a specific tax break was introduced in 2008 (up to $20 \%$ of a project's eligible costs, to a maximum of 2 million euros), and a specific fund is available, ${ }^{17}$ which is managed by the Centre National du Cinema with the support of other government departments. ${ }^{18}$ There are other forms of direct public support focusing on R\&D in the field of audiovisual and cinema. This is the case of the specialized French funding entity "Recherche et Innovation en Audiovisuel et Multimédia", managed by the Centre National du Cinema. The European Commission has also provided aid to video game and audiovisual industries through various MEDIA Programmes (2007-2013). Initially, it was included as development support for multimedia projects. Support is now available for both cinema and the video game industry within the Creative Europe programme. ${ }^{19}$ As well, the Council of Europe has set up specific support schemes for production, digital masters, and theatres with Eurimages, but the output does not appear to be very high at the moment (De Vinck, Lindmark, 2012: 108).

In conclusion, the advent of the Internet and mobile technology ushered in newcomers as well as disruptive and innovative business models into the video game industry. These new comers and their innovative scenarios are re-shaping the landscape of the traditional industry. Thus, on line and mobile games acted as an engine of change within the video games industry. Despite its relatively short history, the video game industry has become nowadays a huge economic sector addressing every kind of channel. In the cultural industries, video games occupy thus a unique place. Most creative industries are based on the value of contents, while a video game mostly relies on interaction. Legacy publishing is grounded in the production of content (books, films, news...) that will be reproduced in a similar fashion, so as to be distributed to an audience that will consume the same works along like patterns. On the opposite, videogames require making available a software enabler that will only develop itself in the interaction with the player, in a way that will differ for each player. Therefore, the strategy of the game companies is to increase the engagement of the user and to try to monetize his willingness to go on with the game. In other words, this difference does not simply influence the nature of the projects. It also has a significant impact on how video game companies perceive, design and organize innovation, and on how they are perceived by policy-makers.

\subsection{Is there a need to depart from "silo thinking" in the cinema industry?}

There is much current disagreement among newcomers and legacy players about the ways to finance creation. The latter (legacy content or infrastructure providers) argue that the former

\footnotetext{
${ }^{17}$ Fonds d'aide au jeu vidéo: Fajv: http://www.cnc.fr/web/en/support-fund-for-videogames.

${ }^{18}$ See an assessment in Centre National du Cinema (2016).

19 Education, Audiovisual, and Culture Executive Agency: http://eacea.ec.europa.eu/index en.php and the Creative Europe Desks (http://ec.europa.eu/culture/tools/creative-desks_en.htm).
} 
(newcomers, OTTs) are not taking their fair share of the load, benefiting from both content and infrastructure without making their required contributions, and are siphoning off audiences and revenues. The new players are certainly disrupting legacy business models and displacing revenues, ending former cross-subsidy models. Nonetheless, the benefits attributed to OTTs seem a bit more difficult to establish (Simon, 2016b).

The case of cinema is noteworthy because of its paradigmatic character. This exemplary character of cinema is due, on the one hand, to the seniority (Benghozi and Delage, 2000; Benghozi, 1989) and the particular scale of public policies in this sector and, on the other hand, to the challenges of possible adaptation of these policies triggered by the evolutions described in Section 1. It is precisely this paradigmatic role of these "vertical" policies in European countries (and beyond Europe, as well), which calls for a comparison with the video game industry.

In particular, it may be worth taking a closer look at France, since its funding system, developed over decades, has often been presented as a model. The French system (specific tax, Centre National du Cinema) has been largely copied and inspired many systems in other sectors (audiovisual, animation, video games) as in other countries (Sojcher, Benghozi, 2003). The system can be seen as obligatory savings monitored through a public body, the Centre National du Cinema. This entity collects money from the box office through a tax (TSA) added to the price of the ticket, and then re-allocates these funds to production and distribution, but to a lesser extent. The system was meant to fund supply, as the emphasis of public policies was to increase the level of financing. Recently, it came under criticism for leading to overproduction of films. Nevertheless, French policy-makers did continue to follow their traditional approach, "the funding of creation", and have tried to extend the existing mechanisms to new channels (e.g., they have implemented a tax similar to the TSA on $\left.\operatorname{ISPs}^{20}\right)$.

Some other European Union Member States have mandated financial contributions when these players (ISPs, mobile operators) distribute or "package" audio-visual works. The principle adopted in France was that each company making money from the use of work should contribute to the funding of the creation, and many other European Union regulators agree with this principle. ${ }^{21}$ The Media Forum set up by the European Commission in 2011 came up with some related principles to "adapt financial support for audio-visual creation" (solution 4) and "to treat like as like" (solution 5), mostly in the latter case for regulation and tax issues (European Union Media, Forum Executive Summary, 2012 22 ).

Similarly, the Forum d'Avignon came up with recommendations in line with these approaches to "involve new players in financing creation" (Salmon 2012: 50), suggesting the usual approaches of both the introduction of a tax on connected equipment in the wake of the French report (Lescure, 2013), and mandating obligations "consistent with their influence". This principle sounds nice and (almost) fair, but it leaves open the trickier question of how to implement it. This would require some robust evidence and a clear basis for quantifying their contribution, and defining the "influence" and even the "consistency", as most of the revenues derived from content are indirect (advertising) and not direct sales to customers. Indeed, the case is far more complex, as we are facing sophisticated multi-sided markets. Needless to add, these approaches distort the market and would need a thorough case-by-case analysis to prevent any unexpected consequences, and, according to Salmon (2012: 50-51), "current funding arrangements penalize the emergence of international structures". The report pleads

\footnotetext{
${ }^{20} 3 \%$ of revenues derived from this channel of distribution.

${ }^{21}$ For a review of the funding film policies in some European Union countries, see Wutz, Perez (2014: 93-107).

${ }^{22} \mathrm{http} / / /$ ec.europa.eu/information_society/media taskforce/doc/pluralism/forum/exec_sum.pdf
} 
rightly for more coordination at the European Union level, but also for "rebalancing power," which, without the legal and regulatory teeth required, may amount to little more than wishful thinking. This approach may again miss the point in a digital networked environment that is now jeopardizing the territorial basis of this funding system, based on the collection of the tax by national movie theatres, with the growth of alternative distribution channels and services provided by suppliers located outside the French territory or even outside the European Union.

In this fundamentally global context, the legacy media industries in the European Union, whatever their relative strengths, are fragmented and not in a position to make the best of their own strengths. They are most often followers, not trendsetters. European Union policies could contribute to bringing all the pieces of the puzzle together, by enabling further cooperation and coordination across Member States. To take into account the new parameters of the digital environment, policy makers need to move forward and beyond simply supporting supply (a logic of production). One can wonder whether a departure from "silo thinking" is required: e.g. away from partitioning industrial policies and from any "automatic funding" mechanism.

\section{Conclusions: Towards new forms of public intervention?}

The evolution of the CCI development models and the changes brought by technology raise questions about how to reconsider the role of public intervention in the area of culture. The cross-comparison between the two sub-sectors we reviewed reveals some interesting features. First, the case of video games illustrates how an industry can adjust and keep on innovating. It shows many of the innovative characteristics that can be observed, but with less intensity, in other CCIs. Young companies appear to strongly challenge legacy publishers with disruptive propositions - original products, on-line and mobile channels of distribution, experimental business models - and the real capacity to monetize these by accessing a massive and global audience. Policies were designed to attempt to optimize the benefits of these companies' growth within a global market, and were part of a broader policy in countries such as Canada and South Korea.

Second, the case of cinema shows that an incremental innovation model has also emerged within the industry with ICT industry suppliers, like specialized middleware providers for the video game industry (Benghozi et al, 2015). In a fast-changing technological environment, the relationships between the two complementary visions of the industry (technological/artistic) are evolving towards a more technology-oriented vision. Within a complex value network, some of the players are able to achieve commercial autonomy, thus extending their customer base to other sectors such as video games, broadcasting, advertising, and medical imagery.

One may need to move forward and beyond the mere logic of supply to a logic of production to take into account the new parameters of the digital environment. Increased R\&D expenditures would be then more likely to irrigate the whole sector. Actually, there is a possible virtuous path that blends these dimensions: the emerging 3D brought market changes, allowed digital distribution to grow (as with a company like UFO) and pushed theatres to get the necessary equipment, moving away from the catch-22 situation of producers not willing to use 3D for a lack of 3D theatres. This will require departing from "silo thinking," the partitioning of industrial policies, and any kind of "automatic funding" mechanism in a fast-changing world. This also means bringing together all kinds of expertise needed through policies in education, science and technologies. Besides, appropriate ways to finance risk should be sought from a more global viewpoint within the global ecosystem.

Until now, the history of CCIs has mainly been about the ability of technology suppliers to step into the value chain: think about Philips, Sony, RCA or Marconi. 
Technology suppliers left the value chain largely unchanged: they sought primarily to provide content for the technologies they offered and thus created alternative content producers (Sony Music or Polydor). The current situation, in a networked economy, is significantly different. Technological dynamics reconstitute the partitioning of distribution channels that recent technological convergence has helped to integrate. They structure distinct integrated channels similar to those that can be found in the video game industry (consoles, mobile, personal computer). Therefore, they are potential levers of an explosion of the content market.

The radical nature of current innovation processes, from a global perspective, should lead to overcoming old R\&D perceptions, for example the gap between incremental and disruptive innovations. Different types of innovations are not juxtaposed but rather substitutes in modular arrangements. This has had a great impact on investment strategies: the pace of technological change in networks and content requires massive investments to deploy the necessary infrastructure and the appropriate content production.

Benghozi et al. (2009) argue that this is a new challenge for the public actors in charge of CCIs. Operators' incentives to invest in increasing network capacity are related to anticipating demand for services and content. Otherwise, content providers consider it necessary to increase capacity (regardless of current demand), as they believe they will always find takers. Therefore, the question arises: who takes the investment risk, and how it is compensated? In other words, can the marketing of content be an efficient revenue model to fund innovations in digital networks? Regulation has always had a supply perspective: it focuses on how economic actors downstream can have access to resources made upstream. The issue of sharing risk investments in the value chain thus calls for a reversal of perspective in order to finance the significant risks associated with breakthrough technological innovations.

\section{References:}

Barge-Gil, A., M. J. Nieto, and L. Santamaria. 2011. "Hidden Innovators: The Role of Non-R\&D Activities." TechnologyAnalysis \& Strategic Management 23(4): 415-432.

Benghozi P.-J. 1989. Le cinéma, entre l'art et l'argent, L’Harmattan, Paris.

Benghozi P.-J., Delage C. 2000. Histoire économique du cinema français (1895-1995), L’Harmattan, Paris.

Benghozi P-J., L. Gille, and A. Vallée. 2009. «Innovation and Regulation in the Digital Age”, in A Call for New Perspectives, in Telecommunication Markets Drivers and Impediments (ed. by Curwen P., J. Haucap et B. Preissl), Springer.

Benghozi P.-J., and T. Paris. 2014. «L'économie culturelle à l'heure du numérique: une révolution de l'intermédiation », in La culture et ses intermédiaires. Dans les arts, le numérique et les industries créatives, edited by Laurent Jeanpierre, Olivier Roueff, éditions des archives contemporaines, pp. 155-168.

Benghozi P.-J., and E. Salvador. 2014. "Are traditional industrial partnerships so strategic for research spinoff development? Some evidence from the Italian case", Entrepreneurship\&Regional Development: an International Journal, 26(1-2): 47-79.

Benghozi P.-J., Salvador E. 2015. " Technological innovation and R\&D, the disregarded dimension of the creative industries: the case of book publishing", Special Issue, Les industries culturelles européennes dans la globalisation numérique, Economia della Cultura, XXV(2): 255-267.

Benghozi P.-J., Salvador E. (2016) "Investment strategies in the value chain of the book publishing sector: how and where the R\&D someway matter in creative industries?", Technology Analysis\&Strategic Management, vol. 28, n. 5, pp. 568-582.

Benghozi P.-J., E. Salvador, and J.-P. Simon. 2015. "Models of ICT Innovation. A Focus on the Cinema Sector", edited by Bogdanowicz M., European Commission, JRC Science and Policy Report, pp. 1144,http://is.jrc.ec.europa.eu/pages/ISG/EURIPIDIS/documents/JRC95536.pdf

Benghozi, P.J, and J.-P. Simon. 2016. "Out of the Blue: The Rise of CDN Networks", Communications \& Strategies, 101-1st quarter: 107-128. 
Benhamou F. (2014), Le Livre à l'heure numérique. Papier, écrans, vers un nouveau vagabondage, Paris, Seuil.

Brandellero, A. M. C., and R. C. Kloosterman. 2010. 'Keeping the market at bay: exploring the loci of innovation in the cultural industries', Creative Industries Journal, 3(1): 61-77.

Chantepie P., and A. Le Diberder. 2010. Révolution numérique et industries culturelles, Editions La Découverte, Paris.

Choi J. 2010. "Challenges and strategies of local cultural cluster promotion policies in Korea", The Service Industries Journal, 30(5): 763-775.

Centre National de la Cinématographie (CNC). 2016. "Support for the Creation of Video Games. 2015 results". http://www.cnc.fr/web/en/publications/-/ressources/10508209

Cooke P., and L. De Propris. 2011. "A policy agenda for EU smart growth: the role of creative and cultural industries", Policy Studies, 32(4): 365-375.

Corallo A., G. Passiante, A. Prencipe. 2007. The Digital Business Ecosystem, Cheltenham, UK, Edward Elgar Publishing.

Cunningham, S. D., T. A. Cutler, G. N. Hearn, M. D. Ryan, and M. A. Keane. 2004. "An Innovation Agenda for the Creative Industries: Where is the R\&D?" Media International Australia Incorporating Culture and Policy: Quarterly Journal of Media Research and Resources, 112: 174-185.

De Prato, G., C. Feijóo, D. Nepelski, M. Bogdanowicz, and J.-P. Simon. 2010. "Born digital/ Grown digital. Assessing the future competitiveness of the EU video games software industry", JRC Scientific and Technical Report, http:///ipts.jrc.ec.europa.eu/publications/index.cfm

De Prato. 2014. "The video games industry", in De Prato, G., Sanz, E., Simon, J.P, (ed.) (2014), Digital Media Worlds; The new media economy, Oxford, Palgrave, pp. 163-179.

De Prato, G, and J.-P. Simon. 2015. "Global trends in mobile: A new global landscape for supply and demand" in Aguado; J., M., Feijóo; C., Martínez, I.J., (eds), Emerging Perspectives on the Mobile Content Evolution, IGF, Hershey, Pennsylvania pp.1-31.

De Vinck, S. And S. Lindmark. 2012. Statistical, ecosystems and competitiveness analysis of the Media and Content Industries: The Film Sector. JRC Technical Reports.

European Audiovisual Observatory (EAO). 2014. Focus 2014, World Film Market Trends, Marché du Film, Festival de Cannes.

Foord J. 2008. "Strategies for creative industries: an international review", Creative Industries Journal, 1(2): 91113.

Foundation for Research, Science and Technology (2003) R\&D Strategy for creative industries-a discussion paper, New Zealand.

Gawer A. (2014), "Bridging differing perspectives on technological platforms: Toward an integrative framework", Research Policy, vol. 43, pp. 1239-1249.

Green, L., I. Miles, and J. Rutter. 2007. 'Hidden innovation in the creative sectors', Manchester Institute for Innovation Research, Working Paper for NESTA.

Jakob D., and B. Van Heur. 2015. "Editorial: Taking Matters into Third Hands: Intermediaries and the Organization of the Creative Economy", Regional Studies, 49(3): 357-361.

Jaw, Y., C. Chen, and S. Chen. 2012. "Managing Innovation in the Creative Industries-A Cultural Production Innovation Perspective" Innovation: Management, Policy \& Practice 14 (2): 256-275.

Jitendra J. 2009. "Two-sided markets and their relevance for competition policy", GRIN Verlag, Germany.

Lash, S., and J. Urry. 1994. Economies of signs and space, London: Sage.

Laur I., Klofsten M., Bienkowska D. 2012. "Catching Regional Development Dreams: A Study of Cluster Initiatives as Intermediaries", European Planning Studies, 20(11): 1909-1921.

Lescure, J. 2013. Culture-acte 2: 80 propositions sur les contenus culturels numériques, Paris, Ministère de la Culture, http://www.culturecommunication.gouv.fr/Actualites/A-la-une/Culture-acte-2-80-propositions-sur-lescontenus-culturels-numeriques. 
McCoskey, J. 2014. "The Future of Entertainment - Merging Technology and Content", www.mpaa.org/thefuture-of-entertainment-merging-technology-and-content/\#.U4M7HIW-iUk

Miles I., Green L. (2008), Hidden Innovation in the Creative Industries, NESTA report, July, pp. 1-81.

Ministry of Economic Development. 2012. Growth and Dynamics of the New Zealand Screen Industry, Evaluation Team, April.

Mobile Game Arch Roadmap. 2013. www.mobilegamearch.eu/wp-content/uploads/2013/09/Mobile-GameArch_D33_13September_2013_v20.pdf

Müller, K., C. Rammer, and J. Trüby. 2009. "The Role of Creative Industries in Industrial Innovation." Innovation:

Management, Policy \& Practice 11 (2): 148-168.

Netflix. 2014._Annual Report 2013, http://ir.netflix.com/secfiling.cfm?filingID=1065280-14-6\&CIK=1065280

Newzoo. 2015a. US \& China Battle for $n^{\circ} 1$. Casual Games Sector Report 2015. http://www.newzoo.com/insights/casual-connect-free-report-us-china-battle-for-1-worlds-top-gamesmarkets/\#5jqIdSBpVlf817sr.99

Newzoo. 2015b. The Mobile Gaming Landscape 2015.

Noreau, J. 2013. "Entre le réel et le virtuel : l'industrie du jeu vidéo au Québec», Desjardins Etudes Economiques, https://www.desjardins.com/ressources/pdf/per1113-f.pdf?resVer=1385157041000

Potts, J. (2009) 'Introduction: creative industries and innovation policy', Innovation: management, policy \& practice, 11(2), pp. 138-147.

Salmon, K. 2012. "The manufacturing of innovation Management \&creation, perspectives for economic growth", Report for the Forum d'Avignon.

Simon J.-P. 2015. "Amazon déclare la guerre des contenus". http://www.inaglobal.fr/numerique/article/amazon-declare-la-guerre-des-contenus-8103

Simon, J.P. 2016a. "User generated content. Users, community of users and firms: toward new sources of coinnovation? info, 18(4): 4-25.

Simon J.-P. 2016b. “L'OTT, un casse-tête pour les régulateurs ». http://www.inaglobal.fr/numerique/article/lott-un-casse-tete-pour-les-regulateurs-9246

Simon J.-P., P.-J. Benghozi, and E. Salvador. 2015. "The new middlemen of the digital age: the case of cinema", info, 17(6): 97-115.

Sojcher F., Benghozi P.-J. 2003. Quel modèle audiovisuel européen ?, L’Harmattan, Paris.

Tran Y., Hsuan J. and Mahnke V. 2011. "How do innovation intermediaries add value? Insight from new product development in fashion markets", $R \& D$ Management, 41(1): 80-91.

UNESCO. 2005. Convention on the Protection and Promotion of the Diversity of Cultural Expressions. www.unesco.org/new/en/culture/themes/cultural-diversity/2005-convention.

Watson A., and C. Taylor. 2014. "Invisible Agents and hidden Protagonists: Rethinking Creative Cities Policy", European Planning Studies, 22(12): 2429-2435.

Wi, Jong H. 2009. Innovation and Strategy of Online Games, Imperial College Press.

Wutz, J., and V. Pérez. 2014. Dissemination of European cinema in the European Union and the international market, Jacques Delors Institute, http://www.notre-europe.eu/media/disseminationeuropeanfilm-wutzperez-nejdi-ifa-unifr-nov14.pdf?pdf=ok 